\title{
Augustin Güntzer: eine eindrucksvolle Patientengeschichte aus der Reformationszeit
}

Fabian Brändle

Korrespondenz:

Dr. phil. Fabian Brändle

fabr[at]gmx.ch
Augustin Güntzer hatte ein schweres Leben. Im Jahre 1596 im elsässischen Obernai (damals Oberehnheim) als Sohn eines hablichen, calvinistischen Kannengiessermeisters geboren, war er schon von Kindsbeinen an mit verschiedenen, schweren physischen und psychischen Krankheiten geschlagen. Als frommer Calvinist führte er diese Krankheiten meistens auf einen seine Sünden strafenden Gott zurück. Güntzer war ein sozialer Absteiger, in den Wirren des Dreissigjährigen Krieges emigrierte er mehrmals. Augustin Güntzer beendete sein Leben unglücklich als Wanderhändler auf einer Strasse, on the road, irgendwo um Basel.

Dieses Leben hat Güntzer in einer der ersten deutschen Handwerkerautobiographien auf mehreren hundert Seiten minutiös aufgezeichnet und mit einigen schönen Zeichnungen illustriert. Im Folgenden beschäftigen mich sein Umgang mit Gesundheit und Krankheit, seine Deutungen der Leiden, kurz: sein Leben als Patient.

Güntzer litt an einem Geburtsfehler, einem «Karnoeffel» (Hodenbruch). Der herbeigerufene Chirurg konnte diesen Schaden nicht beheben. Als Bube in Obernai geriet Güntzer mehrfach in Gefahr. Ein Katholik stiess ihn in den Mühlbach und wollte ihn ersäufen, so dass Güntzer beinahe ertrank. Eine wildgewordene Kuh nahm ihn auf die Hörner und warf ihn mehrere Meter durch die Luft. Eine Menschenmenge lief zusammen und hielt den Knaben schon für tot. Die Ärzte verschrieben Medikamente, doch führte Güntzer als Erwachsener sein damaliges Gesunden auf das direkte Eingreifen Gottes zurück. «Es wirdt mihr aber durch Gottes Genadt besser von Tag zu Tag, Gott sey Danck um sein Hilff.» Für Güntzer war Gott der beste Arzt, «diweill ich weiss, dass kein besser Helfffer, Artzet, ist im Himel undt auf Erden dan du aleine.» In einer anderen Passage bezeichnete Güntzer Gott explizit als «hoegsten Artz», viel höher also als die irdischen Physici.

Immer wieder flehte Güntzer Gott um Vergebung seiner Sünden an. Vergebung war für ihn die Voraussetzung für Gesundung an Leib und Seele.

Interessant ist, dass seine an sich streng calvinistischen Eltern auch einmal einen jüdischen Arzt namens Lazarus von Dambach riefen, der den Urin des jungen, lange Zeit fiebrigen Patienten beschaute und Kräuter verordnete. Güntzer notierte, diese seien «in dem Ancken zu roesten, des Nachts eins auff die Stirn, daz ander auf den Nabel zu legen, mihr ein ander Secklin in ein Kandten zu legen, Wermudwein darab zu trincken, welches ich nuhr eine Nacht ge- praucht habe.» Die Medikamente zeigten seiner Ansicht nach Wirkung, denn am nächsten Tag war Güntzer fieberfrei. Es brauchte aber noch einige Monate, bis er wieder richtig gesund und als Kannengiesserlehrling arbeitsfähig war.

Auf seinen ausgedehnten Gesellenreisen (16171622), die ihn durch halb Europa führten, litt Güntzer phasenweise Hunger, ja einmal wäre er beinahe verhungert und brach aus Erschöpfung zusammen. Besonders gefährlich für Leib und Seele war es in katholischen Landen, wo er Räuber und «falsche Minch» (Mönche) fürchtete und die Obrigkeiten «Ketzer» erbarmungslos verfolgten. Im bekannten Wallfahrtsort Loreto empfand er die Luft als verpestet von Weihrauch. Hier kommt Güntzers bisweilen militanter Antikatholizismus voll zum Tragen.

Oft fror der Geselle auch erbärmlich, namentlich im Baltikum, wo ihm einmal beinahe die Nase, einmal fast die Füsse erfroren. Zudem plagte ihn ein schlimmer Hautausschlag, der ihn sogar auf Suizidgedanken brachte. Dies verweist auf psychische Probleme, die Güntzer entsprechend der antiken «Säftelehre» (auch «Temperamentlehre» genannt) als «Melancholie» bezeichnete. Dass Güntzer seine «melancholische» Veranlagung auf die Sternenkonstellation bei seiner Geburt zurückführte, ist nicht überraschend. Astrologische Konzepte waren auch in der gelehrten Medizin seiner Zeit durchaus verbreitet.

Nach der obligatorischen Wanderzeit als Geselle heiratete Güntzer 1623 die wohlhabende Colmarer Meisterwitwe Anna Göckel. Er liess sich in der Reichsstadt Colmar nieder, wo er das Bürgerrecht erwarb und als zünftischer Kannengiessermeister arbeitete. Die Stadt Colmar war konfessionell gespalten in Katholiken und Protestanten, welche die Mehrheit stellten. Die Calvinisten waren innerhalb des Protestantentums eine kleine Minderheit.

Im Jahre 1628 eroberten katholische kaiserliche Truppen die Stadt und stellten den Protestanten das Ultimatum, zu konvertieren oder die Stadt zu verlassen. Güntzer optierte als einer von wenigen Handwerkern für die Emigration, entschloss er sich doch, nach Strassburg zu gehen. Dort musste er harte Wachtdienste leisten. Das gehörte zu den Bürgerpflichten. Die Wohnung war feucht und ungesund. Seine Frau und der jüngste Sohn Augustin überlebten das Strassburger Exil nicht. Er betete oft, dass Gott ihm eine neue Ehefrau schenke, seine Gebete blieben aber unerhört.

Im Jahre 1632 konnte Güntzer nach Colmar zurückkehren, doch mied man ihn als Calvinisten 


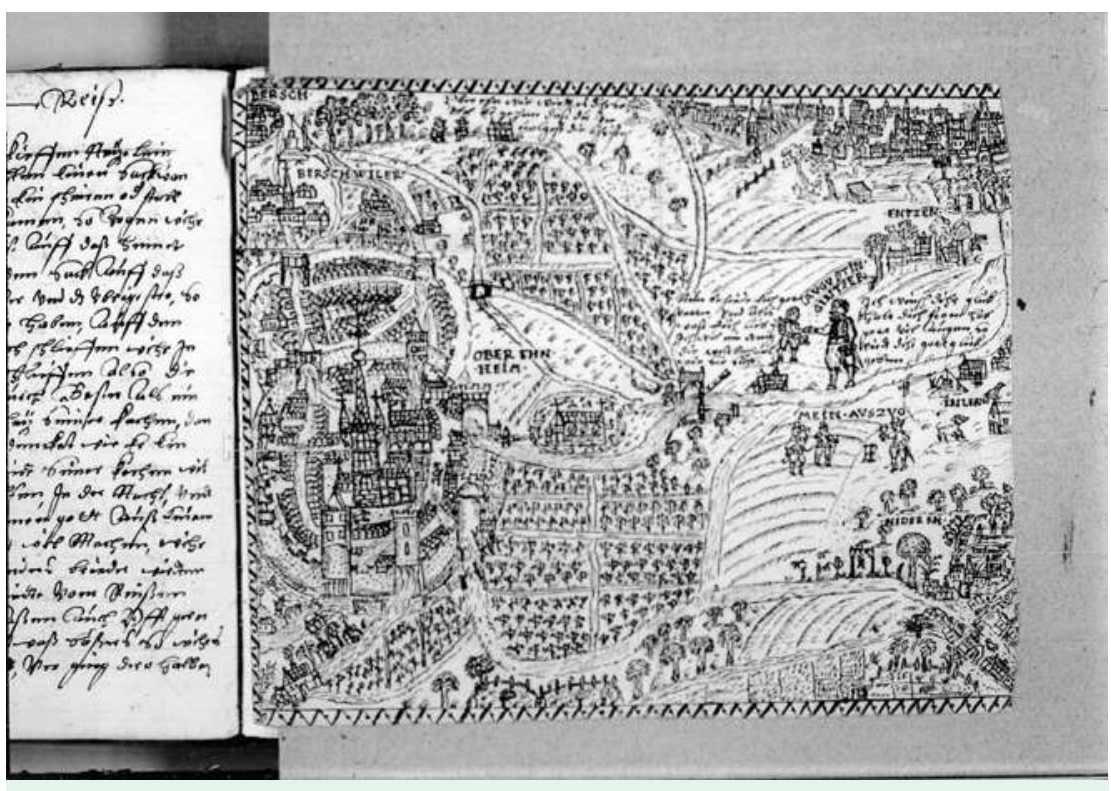

«Augustin Güntzer tritt seine gefahrvolle Gesellenwalz an und verabschiedet sich von seinem Vater.» (Quelle: [1].)
Mehrfach ging Güntzer nach Sulzbach in die Vogesen (Gregoriental) zum dortigen «Sauerbrunnen», um zu kuren und Linderung seiner Schmerzen zu erfahren, mehrfach auch ins bekannte Heilbad von Baden im Aargau. Er behandelte dort seine schmerzhaften offenen Beine («offene Schenkel»). Nicht immer jedoch waren die Kuren von Erfolg gekrönt. Diese Kuren zeigen uns gleichwohl einen Mann, der sich sehr um seine Gesundheit sorgte und auch Geld in die Hand nahm, um zu genesen, nicht alles Leiden passiv hinnahm, sondern aktiv Schritte in Richtung Heilung unternahm.

$\mathrm{Zu}$ den chronischen Beschwerden traten noch weitere Unfälle hinzu, so in Basel, als Güntzer von den notorisch gefährlichen Metzgerhunden gebissen wurde und erneut lange Zeit nicht arbeiten konnte.

Da ihn die Mehrheit der lutheranischen Colmarer Protestanten verachtete und demütigte und für ihn im Elsass kein Bleiben mehr war, entschloss sich Güntzer erneut zu emigrieren, dieses Mal ins reformierte Basel, wo er jedoch, ganz im Gegensatz zu vermögenden Colmarer Kaufmannsgeschlechtern wie den Vischer, den Sandherr, den Sarasin (aus Metz) oder den Birr, nicht Fuss zu fassen vermochte. Er hatte versucht, sich zusammen mit Tochter und Schwiegersohn als Hausierer durchzubringen. Der Schwiegersohn war Zuckerbäcker, Güntzer trug die Ware aus. Die Kinder machten Güntzer schwere Vorwürfe, er habe ihr Erbe verjubelt, sei sogar ein «Narr». Die Existenzängste der Familie waren enorm und nicht unbegründet.

Es ist nicht klar, wann genau Augustin Güntzer verstarb, wahrscheinlich war es 1657 kurz nach seiner Ankunft in Basel. Güntzers Leben war eine Leidensgeschichte, ein lebenslanges «Martyrium» als Patient und Unfallopfer, wie er selbst meinte. Das als «Martyrium» gedeutete Leben war dem Calvinisten auch Sinnstiftung im Bewusstsein, das ewige Heil zu erlangen, so zumindest ist es aus dem von Stilisierungen geprägten Text zu vermuten. selbstbewusster Vergleich mit dem alttestamenta rischen Heiligen, der alles verloren und dann wieder gewonnen hatte. Dies verweist darauf, dass man die Ausführungen Güntzers nicht für bare Münze nehmen sollte. Autobiographien sind voll von Stilisierungen. Der Autor will ein bestimmtes Bild von sich vermitteln, sich als Opfer oder als Held darstellen. Beides kommt in Güntzers Text zum Tragen.

Vielleicht waren Güntzers chronische Hautprobleme auf die Bleidämpfe zurückzuführen, denen er bei der Arbeit ausgesetzt war. Im Alter plagten den Kannengiesser dann Ängste: Ängste vor der ewigen Verdammnis, Höllenängste und Ängste vor dem Hungertod. Die letzten Seiten der Autobiographie sind von ihnen geprägt, sind praktisch nur noch panisch anmutende Stossgebete. Als Calvinist war er sich der Gnade Gottes offenbar nicht ganz sicher. Die Calvinisten glaubten gemäss ihrem Genfer Lehrer an die doppelte Prädestination, dass Gott nämlich bei der Geburt eines Menschen entscheide, ob er in den Himmel komme oder zur Hölle fahre.

\section{Literatur}

1 Brändle F, Sieber D, Hofer RE, Landert M (Bearb.). Augustin Güntzer. «Kleines Biechlin von meinem gantzen Leben». Die Autobiographie eines Elsässer Kannengiessers aus dem 17. Jahrhundert. Köln, Weimar und Wien: Böhlau; 2002.

2 Brändle F. Augustin Güntzers Irrungen und Wirrungen. Ein schweres Elsässer Handwerkerleben im 17. Jahrhundert. Zeitschrift für die Geschichte des Oberrheins 2010;158:241-57.

3 Honecker M. Christus medicus. Kerygma und Dogma 1985;31:307-23.

4 Mieg P. Les Tribulations d'Augustin Guntzer, bourgeois de Colmar, durant la Guerre de Trente Ans. Annuaire de Colmar 1948:48-65.

5 Sieber D. «Mihr wahren 2 gudte Reiss brieder ... Mein gesel ist zwar der babistischer Religion». Die Autobiographie des calvinistischen Kannengiessers Augustin Güntzer (1596-1657?). Unveröffentlichte Lizentiatsarbeit, Universität Basel 1994. 